\title{
A Vibration Online Measurement System for Car Door
}

\author{
JIANG Ping, HE Lei, ZHANG Yu, WANG Yuguo
}

School of Mechanical Engineering, Nanjing Institute of Technology, Nanjing 211167, China;

jiangping@njit.edu.cn,helei1101@163.com, zy586187@163.com, wangyuguo@njit.edu.cn

Keywords: car door vibration, measurement system, online measurement test.

\begin{abstract}
The structural properties of automobile door have important influence on the safety and reliability of the vehicle. In order to obtain the actual working vibration characteristics of vehicle door, firstly, according to the complex condition, sensors arrangement scheme was determined based on the vibration mode characteristics of the door system that under force hammer excitation; secondly, a car door on-line vibration measurement system was built; then, vibration measurement test was done under level load, pavement with a reduction bar and macadam pave conditions. Results show: The system can measure the door vibration signal in real time and realize the signal frequency characteristics analysis.
\end{abstract}

\section{Introduction}

The vibration characteristics of car door are important study contents during the new car $R \& D$ process, and give important guidance in how to maintain the vibration-proof and the structural properties of the car door for automobile design. The low-order modes of car door structure not only reflect the stiffness, but also have great influence on vehicle internal structure noise. Because of theses, lots of scholars did research on the vibration characteristics of the vehicle or automobile doors[1]. Meng Liu[2] and others studied on the vibration of the back door in combination with the method of working condition transfer path and finite element simulation; Yanxia Ge[3] designed a kind of auto testing apparatus for the debugging of automobile door after finishing assembling the car. Shunliao Yan[4] and others did research on the automatic detection for boxcar door states with the boxcar door state detection system which was based on the image processing technology; Wenbo Luan[5] and others explored the relationship between the start flutter and the vehicle transmission; Xin Zeng[6] studied on the modes and stiffness of the front door according to the method of finite element analysis, and to some degree, the research gave guidance in the design methods of automobile door structure. Theoretical or simulation analysis is often difficult to describe the car door vibration quantitatively, and it's also hard to reveal the car door vibration rule during the car running process with the method of taking force hammer excitation to obtain the door vibration characteristics when still. Designing a kind of online car door vibration measurement system to measure the automobile door vibration signals in real time under different driving conditions has great engineering value to evaluate the vehicle preference and improve the technology of car door structure design.

\section{Selection of car door vibration measuring points}

The arrangement of sensors for car door vibration measurement is the key to obtain the automobile door vibration signals. According to the principle of experimental mode analysis, each point in the whole car door structure generates a different vibration response if any point a was applied an excitation Fa. Considering that the damping of the whole door structure is small under free mode analysis, the automobile door can be simplified as a liner elastic system with $\mathrm{N}$ degrees of freedom. The vibration response displacement of point $\mathrm{b}$ in the car door structure was denoted as $\mathrm{Xb}$, and the corresponding relationship between the excitation point a and the response point $\mathrm{b}$ can be expressed by the transfer function $\mathrm{Hba}=\mathrm{Xb} / \mathrm{Fa}$. When the car door was knocked by the force hammer, the excitation can be treated as the unit impulse signal. To this end, the car door vibration modes under 
force hammer excitation can reflect the distribution characteristics of the vibration intensity of each point in the door.

In order to obtain the vibration intensity distribution of the door under the action of external force, the door was stimulated by the force hammer when it was closed, and after that, the door vibration response signals under the treatment of force hammer were processed by the mode analysis software N-Modal 510. The modes of vibration are shown as Figure 1, and the vibration frequency of each mode can be saw in Table 1. The car door vibration measuring points (as Figure 2 shows) were confirmed according to the modes of vibration (as shown in Figure 1). The whole car door was arranged with 8 sensors to pick up its signals.

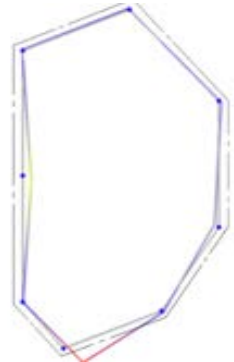

(a) The first-order mode

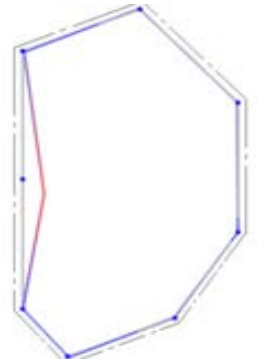

(b) The second-order mode

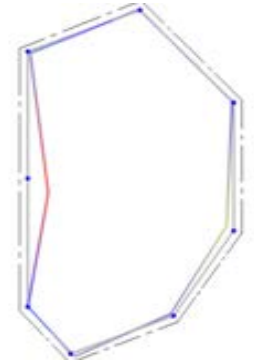

(c) The third-order mode

Figure 1 . The modes of vibration under the force hammer excitation

Table 1 . The vibration frequency of each mode

\begin{tabular}{|c|c|}
\hline Orders & The mode frequency(Hz) \\
\hline The first-order mode & 162.15 \\
\hline The second-order mode & 329.08 \\
\hline The third-order mode & 385.76 \\
\hline Measuring point 7 & Measuring point 6 \\
\hline Measuring point 8
\end{tabular}

Figure 2. The arrangement of sensors for car door vibration measurement

\section{Construction of car door vibration measurement system}

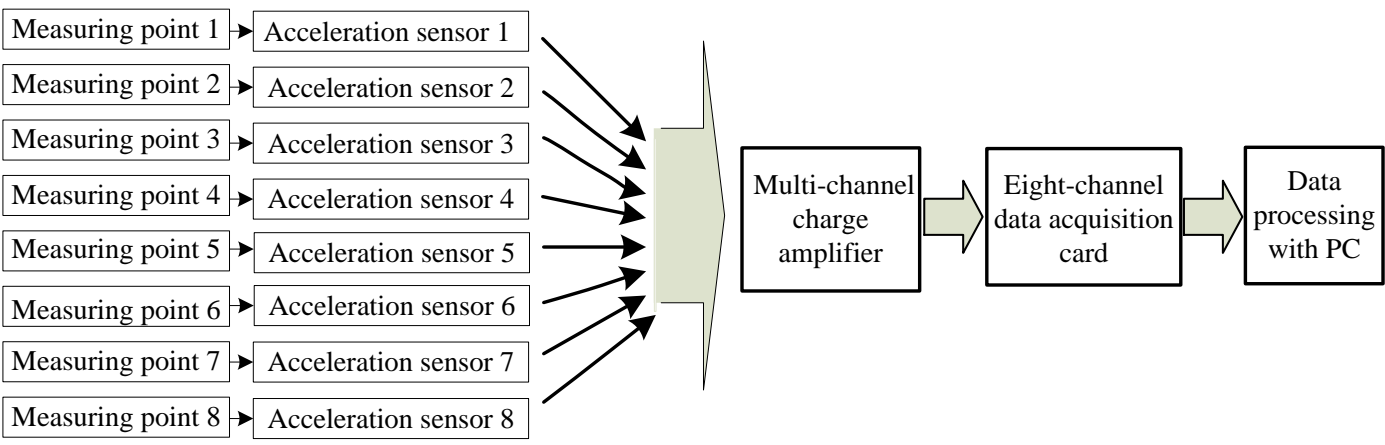

Figure 3. The structure chart of the door vibration measurement system 
In accordance with the arrangement of car door vibration measuring points shown above, the structure chart of the door vibration measurement system for a minibus was established and is shown in Figure 3. Eight vibration acceleration sensors were installed on the door, and the data processing and analysis relied on the data acquisition software MI-7801 (made by Yiheng Hangzhou). The arrangement of test equipment can be saw in Figure 4. Sensor installation location is shown in Figure 4(a), and the position of the PC for data processing is shown in Figure 4(b).

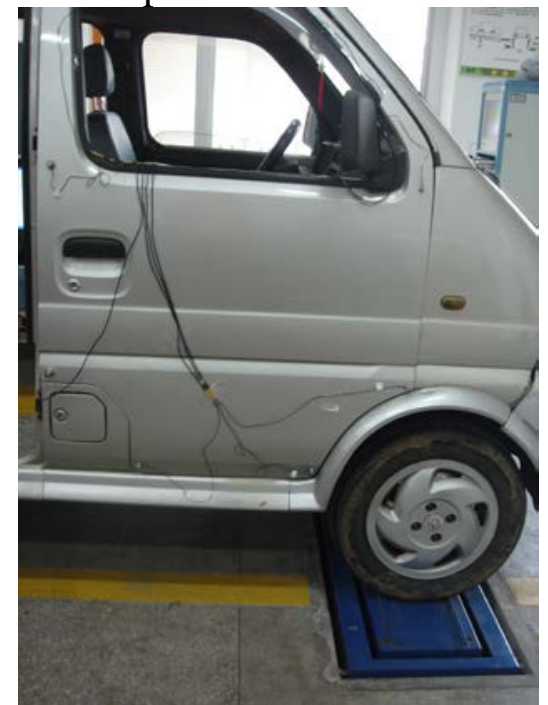

(a) The sensor installation location

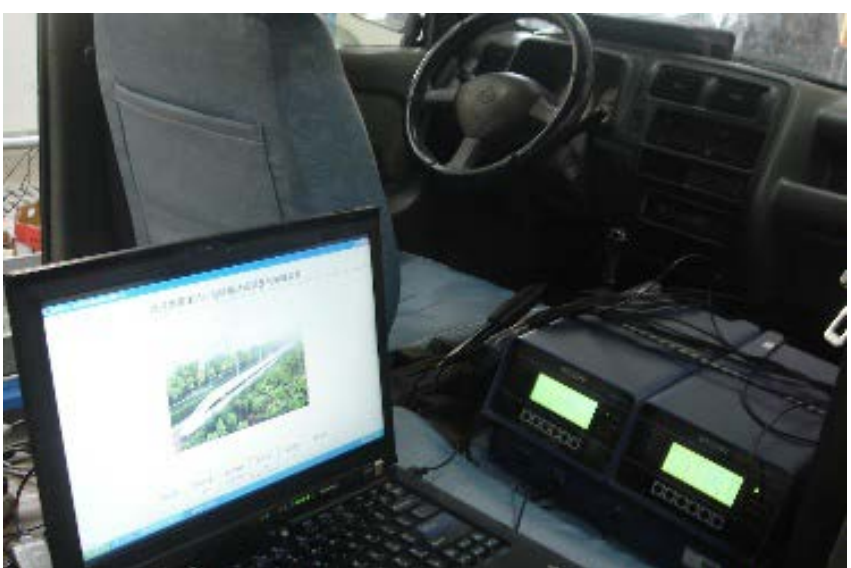

(b) The PC location

Figure 4. The placement of detection equipment

\section{Experimental study}

In this paper, the car door vibration tests had been done respectively under three typical car running conditions (including the level pavement, the pavement with a reduction bar, and the macadam pavement). The minibus run on the level pavement with the speed of $0 \sim 50 \mathrm{~km} / \mathrm{h}$. Detecting the door vibration response. The minibus run on the pavement with a reduction bar with the speed of $20 \mathrm{~km} / \mathrm{h}$. Detecting the door vibration response. The same car run on the macadam pavement with the speed of $20 \mathrm{~km} / \mathrm{h}$. Detecting the door vibration response.

When testing, the system sampling frequency was set as $1280 \mathrm{~Hz}$, the sampling length was set as 2048, and the frequency solution was set as $0.625 \mathrm{~Hz}$. The minibus run on the level pavement with the speed of $0 \sim 50 \mathrm{~km} / \mathrm{h}$. The door vibration response signal detected by sensor 1 installed on the front door and its self-PSD are shown in Figure 5. The door vibration frequency concentrated mainly on $94.8 \mathrm{~Hz}$ and $171.1 \mathrm{~Hz}$.

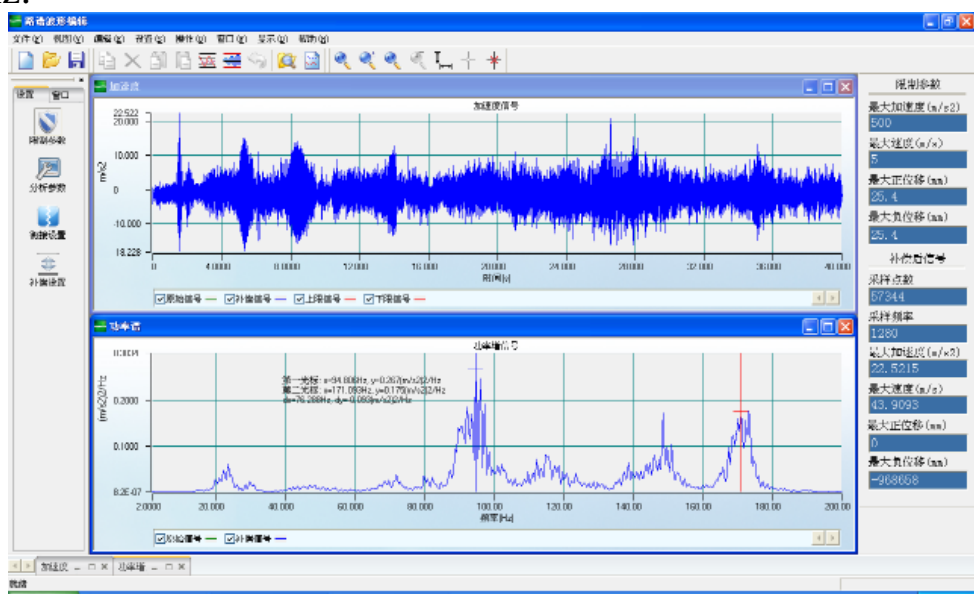

Figure 5. The car door vibration signal when car running on the level pavement with the speed of 0 50 km/h 
The minibus passed through the macadam pavement with a speed of $20 \mathrm{~km} / \mathrm{h}$. The door vibration response signal detected by sensor 1 and its self-PSD are shown in Figure 6. The resonance peak turned up when the car door vibration frequency was $117.5 \mathrm{~Hz}$ or $171.1 \mathrm{~Hz}$.

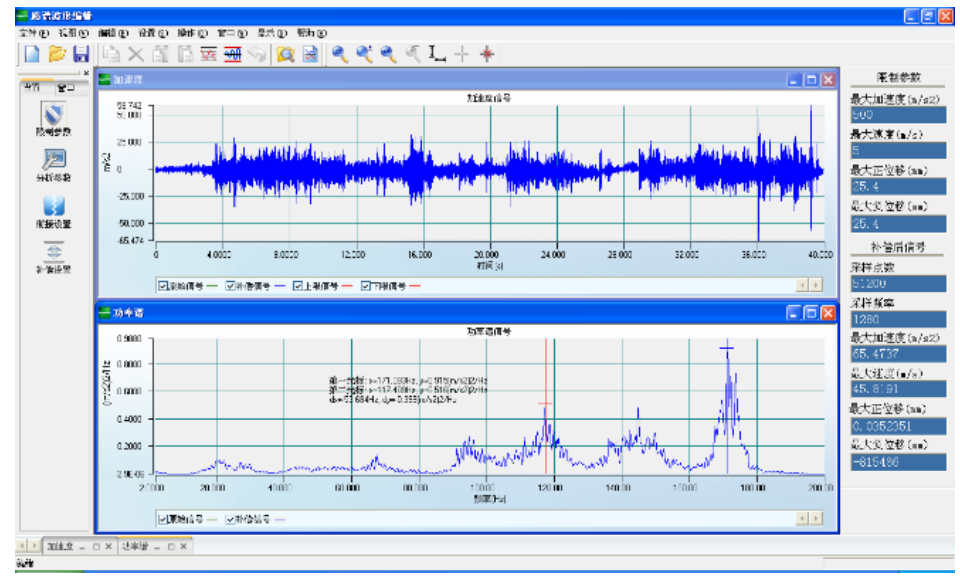

Figure 6. The car door vibration signal when car running on the macadam pavement with a speed of $20 \mathrm{~km} / \mathrm{h}$

The same car passed through the pavement with a reduction bar, and the door vibration response signal detected by sensor 1 and its self-PSD are shown in Figure 7. The door vibration frequency concentrated mainly on $119.8 \mathrm{~Hz}$ and $172.4 \mathrm{~Hz}$.

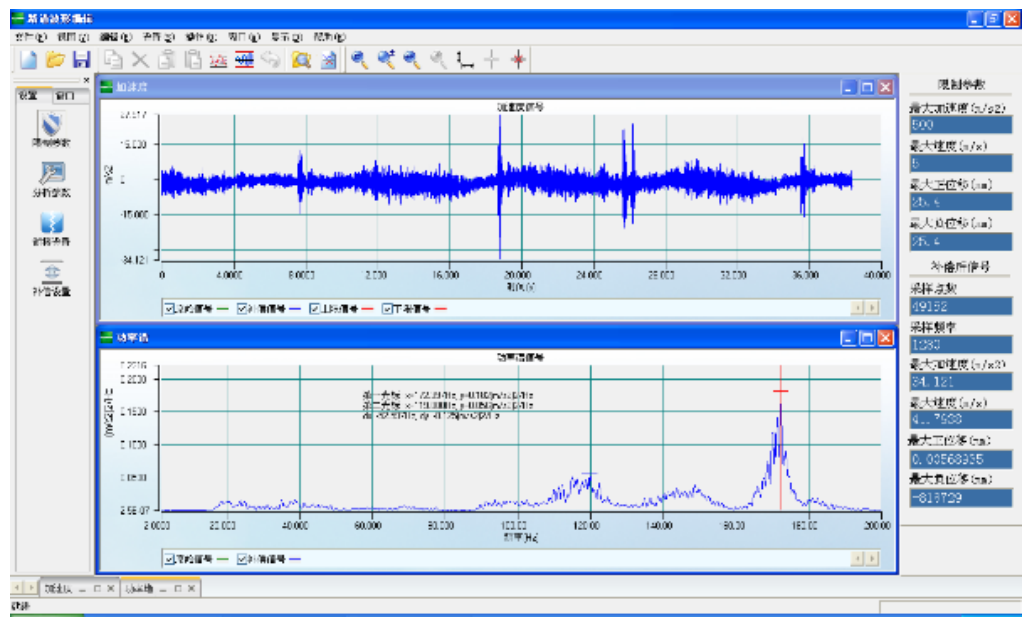

Figure 7. The car door vibration signal when car running on the pavement with a reduction bar with the speed of $20 \mathrm{~km} / \mathrm{h}$

By comparing the frequency distribution characteristics of the door vibration signals under the three different conditions mentioned above, it can be seen that the second resonance peak points of the car door are all in the vicinity of $171 \mathrm{~Hz}$; On the three different pavements, the first vibration peak points of the car door are distributed in the $94-120 \mathrm{~Hz}$ area, and the smoother the pavement is, the lower the peak of car door vibration frequency will be.

\section{Summary}

In order to realize the online measurement of automobile door vibration, the characteristics of the door vibration modes were analyzed by taking the force hammer excitation. Then based on this, the online vibration measurement system for the automobile door was constructed, and the online measurement tests for the door vibration had been done under the three different conditions (including the level pavement, the pavement with a reduction bar, and the macadam pavement) to obtain the frequency characteristics of the door vibration signals. It has instructional significance to the automobile door design. 


\section{Acknowledgments}

Corresponding author: JIANG Ping, Tel:18951962917, jiangping@njit.edu.cn

\section{References}

[1] CHEN Qiong-ying, LIU Cheng-wu, LIANG Hui-quan. Vehicle door vibration analysis by modal test[J]. Journal of Minjiang University, 2012, 33(2): 56-60.

[2]LIU Meng, LU Jing, WANG Xiao-long, WANG Ya-yun, SONG Wan-long. Vibration Noise Identification and Modal Analysis of Back Door Based on Working Condition Transfer Path Methods[J]. Science Technology and Engineering, 2015 (23): 55-58.

[3]Ge Yanxia. Research Application of the Automatic Test Device for Metro Cars[J]. Computer Measurement \& Control, 2015, 23(4): 1253-1255.

[4]Yang Shunliao, Zhang Zhengbing. Automatic Detecting Status of Doors on Boxcar Based on Image Processing[J]. Computer Measurement \& Control, 2012, 20(10): 2606-2608.

[5]LUAN Wenbo, WU Guangqiang. Complex Mode Analysis and Simulation Research of Automotive Driveline Based on Bending-torsional-axial Coupled Vibration Hybrid Model[J]. Journal of Mechanical Engineering, 2015, 51(22): 73-81.

[6]ZENG Xin. The Front Door of Finite Element Modal and Stiffness Analysis based on[J]. Equipment Manufacturing Technology, 2015 (2): 97-98. 